\title{
House prices problem of clustering analysis of 31 provinces and cities in China now Chen Yao
}

Hubei University of Education,Wuhan,China \begin{abstract}
policy now feasible opinions or Suggestions.
Keywords: Housing, Cluster analysis

\section{我国31省市当前房价问题的聚类分析 \\ 陈瑶 \\ 中国武汉湖北第二师范学院}

Abstract: The housing problem, has been China the topic of ordinary people more attention. Can a lot of people will buy a room as the standard of success. In April 2014, according to data released China's 70 large and medium-sized cities housing prices fall month-on-month growth. Search to some relevant information through the network at the same time, consider the rationality of the indexes of the possibility of and access to information, choose a certain representative index, using the relevant statistical software for clustering analysis, and put forward corresponding to relevant

\begin{abstract}
摘要: 房价问题, 一直是中国普通老百姓比 较关注的话题。很多人将能否买的起房当作 成功的标准。从2014年4月公布的相关数据 来看, 中国70个大中城市的房价环比增速有 所回落。同时通过网络搜索到一些相关的资 料, 考虑到指标的合理性以及获得资料的可 能性, 选择具有一定代表性的数据指标, 运 用相关的统计软件对其进行聚类的分析, 并 对现在有关的政策提出相应的可行的意见 或者建议。
\end{abstract}

关键词：房价，聚类分析

\section{一、引言}

房价最开始上涨是从2009年初从北上广 等一线城市开始的, 在当年的第一季度末国 家采取相应的措施对房价进行了宏观调控 使得房价得到了控制。但是从2010年的第三 季度初起, 房价上涨的趋势在二三线城市蔓 延, 此后的一段时间国家一直在密集的出台 相关的措施希望能够控制房价过快的增长。 但是直到目前房价仍然处于一个相对不合 理的位置。造成房价上涨的原因有很多, 我 认为主要有一下几个方面的原因:

海外量化宽松货币政策

以美国为首的西方国家在 2010 年年初以来 为了应对持续低迷的经济使其能够早日摆 脱经济危机的影响。开始采取量化宽松货币 政策。这种政策出现的影响就是世界交易货
币的贬值使得以美元计价的大量商品价格 普遍上扬。房地产作为一种具有投资品属性 的特别商品也得到了资金的追捧。在我国香 港以及澳门地区由于港澳汇率是盯住美元 而非大陆的人民币的。所以在货币政策选择 上没有太多独立性不能及时跟随内地变化, 在美元贬值的同时港币等交易货币也出现 了贬值; 另一原因就是由于资金看多人民币 资金进入香港较为明显, 使得香港住宅的销 售均价近些年也达到了自 20 世纪末年东亚 金融危机以来的新高。正是由于这一系列的 海外的量化宽松政策造成我国目前面临着 输入性通货膨胀，居民消费指数继续走高。 此外, 目前人民币仍面临较大升值压力。这 两方面对于房价增长都是正向的。资金为保 值需要投向房地产行业。人民币的升值的预 期也使海外各路资金购买人民币资产。

供求关系

从供给与需求的关系来看数据来看, 2013 年 1 月到 12 月份销售投资比在 0.95 左右波 动，销售的资金与投资资金能够基本持平。 商品房新开工的面积与销售面积比以及竣 工面积与销售面积比这两个数据自 2013年 以来处于逐步下降态势。从整体上来看, 2013年房地产供求关系基本稳定, 房地产呈 现的总体态势就是供给超过需求。因此, 到 近段时间为止引发此轮房价上涨的原因不 
再是以前的整体供求失衡, 而是投资需求上 涨。

\section{土地成本}

从供给角度来看, 土地成本以及资金成本 而建筑成本对于开发商来说波动不大, 这也 是开发商们主要关注的一点。造成房地产市 场有效供应不足的原因并不是土地供应不 够而是来自于开发商的囤地。据国土部公 告, 2013年全国地方政府在土地利用管理方 面存在 2 万多个问题。其中, 全国 34 个城市、 2147公顷土地违法违规办理审批手续, 征地 补偿安置政策落实不到位, 14 个城市拖欠征 地补偿安置费用 19.82 亿元。在实际的土地 出让方面增长较快并且许多城市在 2013 年 土地出让方面都有所加码。因此不是土地出 让不足造成的房价上涨. 更多的原因来自于 许多已出让的土地未被开发。此外, 土地出 让的结构不合理, 城区内供给逐渐减少, 城 郊外土地供应占绝对比重。

国家相关政策未落实到位

自2009年房价大幅度上涨以来, 国家就连 续密集出台了一系列的调控措施希望借此 来稳定房地产市场。可是从落实的情况来 看, 结果并未达预期。2013年 “国务院办公 厅关于促进房地产市场平稳健康发展的通 知（简称通知）”的出台曾让不少人看到了 房价降温的希望, “通知” 要求普通商品房 要实现有效的供给, 要求地方政府大量推 地，使地王现象得到有效的遏制。“通知” 同时也对销售办法的管理作了明确的要求。

“要能结合当地实际, 合理确定商品住房项 目预售许可的最低规模, 不得分层、分单元 办理预售许可。已取得预售许可的房地产开 放商企业, 要一次性公开所有房源, 严格按 照申报价格, 明码标价对外销售。”可是在 这样严格的要求之下, 全国多数地方仍然未 能达到中央的预期, 甚至离预期越来越远。

\section{二、影响房价水平的指标选择}

对我国各地区的房价问题进行分析, 指标的 选择具有决定性的意义。查阅相关的资料, 我认为影响房价水平的指标具体有: GDP 总量, 居民家庭人均可支配收入, 房价收入 比, 人均GDP。

\section{1、GDP总量}

GDP是国内生产总值的英文简称。它是对 一个国家 (地区) 在核算期内所有常住单位 生产的最终产品的总量的度量, 是衡量一个 国家 (地区) 经济状况的重要指标。近年来, 我国的房地产经济出现了新一轮的繁荣期, 房价持续上涨, 这在相当大的程度上是由我 国经济的持续高速发展带动的。我国近些年 的GDP的增速一直稳定在 $7.8 \%$ 左右, 房价 上涨的速度也相应的稳定在 $5 \%$ 左右。查阅 并分析相关的数据我们可以知道: 房地产与 国民经济有着十分密切的关系, 其具体关系 为国民经济的发展会带动或者制约当地房 地产的发展, 房地产又促进或者带动了当地 经济的发展。因此, 文章将GDP作为一个重 要指标来分析GDP对房价的拉动影响。

2、居民家庭人均可支配收入

居民家庭人均可支配收入是指家庭全部收 入中，可用于支付生活费用的收入。人均可 支配收入是按家庭全部人口计算的平均每 人的生活费收入。人们能够理解接受这样的 一种观念, 那就是收入高的地方房价高。所 以，房价的高低也与当地居民家庭的人均可 支配收入有着密切的联系, 因此, 将居民家 庭人均可支配收入作为分析房价的一个指 标是很有必要的。

\section{3、房价收入比}

“房价收入比” 的具体解释为 “居住单元的 中等自由市场价格与中等家庭年收入之 比”。国内有很多的相关学者将其定义为“居 民收入与房价水平之间的比例”。房价收入 比是目前全球许多国家在分析房地产市场 时的一个重要指标。通过合理的计算房价收 入比，可以对市场的运行有准确的了解，同 时也可以帮助人民决定合理的房产消费方 式，在房地产市场中 “租” 以及 “买” 都是 合理的消费方式。根据房价收入比来选择房 价的消费方式才是合理的消费方式, 所以此 处将房价收入比作为分析的一个指标

\section{4、人均GDP}

人均GDP是一个考虑了人口因素的指标, 如 果我们仅仅只考虑地方的GDP的总收入，而 忽略当地的人口数量, 这样的分析得出的结 论会缺乏一定的准确性。因此, 在选定当地 GDP总收入作为分析的一个指标时, 也同时 
将人均的GDP纳入分析参考的范围, 从而兼 顾经济发展与社会人口发展, 对研究我国各 省市房价是很有必要的。

\section{三、我国 31 省市房价问题的聚类分析}

根据上面的描述, 我们可以对表1进行运算 数据标准化的处理 (公式为: (变量一期望) /标准差), 得到表 2 。对表 1 的数据进行标 准化的处理是为了能对不同纲不同数量级 的数据放在一起对比。对表 2 进行标准化的 数据进行聚类分析得出表 3 , 然后得出相关 的结论。

表1

\begin{tabular}{|c|c|c|c|c|c|}
\hline $\begin{array}{l}\text { 排 } \\
\text { 名.1 }\end{array}$ & 地方。 & GDP(亿元) & 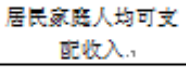 & $\begin{array}{c}\text { 房做入 } \\
\text { 比. }\end{array}$ & $\begin{array}{l}\text { 人均 GDP.1 } \\
\text { (元) .1 }\end{array}$ \\
\hline 1.1 & 广东.1 & 57068.1 & 20384.1 & 8.4.1 & 58678.1 \\
\hline 2.1 & 江苏. & 54058.1 & 20940.1 & 6. 7.1 & 74699.9 \\
\hline 3.1 & 山东.1 & 50013.1 & $17601 .$, & 5. 5.1 & 56463.1 \\
\hline 4.1 & 浙江. & 34606.1 & 24551.1 & 9. 5.1 & 68593.1 \\
\hline 5.1 & 河薾. & 30000.1 & 13983.1 & 5. 6.1 & 34186.9 \\
\hline 6.1 & 河北. & 26575.1 & 14312.1 & 6. 7.1 & 38835.1 \\
\hline 7.1 & 远守.1 & 24801.1 & 16304.1 & 6. 3.1 & 61694.1 \\
\hline 8.1 & 四川. & 23850.1 & 13654.1 & 7.4.1 & 32516.1 \\
\hline 9.1 & 湖北。 & 22250.1 & 14345. & 6.9.1 & 42686.1 \\
\hline 10.1 & 湖雨.1 & 22154.1 & 14380.1 & 5. 5.1 & 36906.1 \\
\hline 11.2 & 上海. & 20101.1 & 28795.1 & 12.1.1 & 90748.1 \\
\hline 12.1 & 䄄治.1 & 19702.1 & $19011 .$. & 9.1.1 & 58056.1 \\
\hline 13.2 & 北京. & 17801.1 & 26473.1 & 14. 5.1 & 94237.1 \\
\hline 14.1 & 安数. & 17212.1 & 14092.1 & 6. 8.1 & 31795.1 \\
\hline 15.1 & 肉察吉. & 15988.1 & 15381.1 & 5. 0.1 & 67603.1 \\
\hline 16.1 & 阵西.1 & 14451.1 & 13103.1 & 7.1.1 & 42752.1 \\
\hline 17.2 & E龙江. & 13692.1 & 13182.1 & 7.4. & 38601.2 \\
\hline 18.1 & 广席. & 13031.1 & $13626 .$. & 5.0 .1 & 30709.1 \\
\hline 19.1 & 江要.1 & 12949.1 & 13844.1 & 7.3.1 & 31835.1 \\
\hline 20.1 & 㺯伍.1 & 12885.1 & 21582.1 & 8.4.1 & 101688.1 \\
\hline 21.2 & 山㕃. & 12113.1 & 13385.1 & 6.1.1 & 34901.1 \\
\hline 22.1 & 声林. & 11938.1 & 14403.1 & 6.2 .1 & 47017.1 \\
\hline 23.1 & 豆夹. & 11459.1 & 15176.1 & 6. 8.1 & 42976.1 \\
\hline 24.1 & 三菂。 & 10310.1 & 13246. & 5. 9.1 & 25157.1 \\
\hline 25.1 & 新猎.1 & 7530.1 & 12158.1 & 6.5 .1 & 38601.9 \\
\hline 26.1 & 童枓.1 & 6802.1 & 11727.1 & 5.9.1 & 26038.1 \\
\hline 27.1 & 甘果. & 5569.1 & 10866.1 & 6.4.1 & 24668.1 \\
\hline 28.1 & 海南.1 & 2855. & 14163.1 & 12. 3.1 & 35491.1 \\
\hline 29.1 & $\dot{\nabla} \boldsymbol{Z}$ & 2327.1 & 14567.1 & 5.0 .1 & 40173.1 \\
\hline 30.1 & 青海. & 1884.1 & 11465.1 & 6.6.1 & 36656.1 \\
\hline 31.1 & 面局. & 701.1 & 11851. & 4. 9.1 & 22981.1 \\
\hline
\end{tabular}

表2

\begin{tabular}{|c|c|c|c|c|c|}
\hline $\begin{array}{l}\text { 排 } \\
\text { 名.1 }\end{array}$ & 地方. & $\begin{array}{c}\text { GDP 标准化数 } \\
\text { 据. }\end{array}$ & $\begin{array}{c}\text { 居民人均可文 } \\
\text { 比收入标准化 } \\
\text { 数据.1 }\end{array}$ & 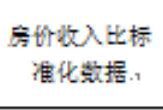 & $\begin{array}{c}\text { 个人 GDP 标概 } \\
\text { 化数据. }\end{array}$ \\
\hline 1.1 & 广东. & 2. 68.1 & 1.00 .1 & 0.53 .1 & 0.54 .1 \\
\hline 2.1 & 江苏.1 & 2. 47.1 & 1. 13.1 & -0.22 .1 & 1. 30.1 \\
\hline 3.1 & 山东.1 & 2. 19.1 & 0.38 .1 & -0.75 .1 & 0.43 .1 \\
\hline 4.1 & 浙江.1 & 1. 12.1 & 1. 94.7 & 1. 02.1 & 1.01 .1 \\
\hline 5.1 & 河南.1 & 0.79 .1 & -0.43 .1 & -0.71 .1 & -0.62 .1 \\
\hline 6.1 & 河北.1 & 0.56 .1 & -0.32 .1 & -0.22 .1 & -0.40 .1 \\
\hline 7.1 & 返宁.1 & 0.43 .1 & 0.09 .1 & -0.40 .1 & 0.68 .1 \\
\hline 0.1 & 四川.. & 0.37 .1 & -0.50 .1 & 0.09 .1 & -0.71 .1 \\
\hline 9.1 & 湖北.1 & 0.25 .1 & 0.34 .1 & -0.13 .1 & -0.22 .1 \\
\hline 10.1 & 湖蔏.1 & 0.25 .1 & -0.34 .1 & -0.75 .1 & -0.50 .1 \\
\hline 11.1 & 上海.1 & 0.10 .1 & 2. 88.1 & 2. 17.1 & 2.07 .1 \\
\hline 12.1 & 㭷崖.1 & 0.08 .1 & 0.70 .1 & 0.84 .1 & 0.51 .1 \\
\hline 13.1 & 北京.1 & -0.06 .1 & 2. 36.1 & 3.24 .1 & 2. 23.1 \\
\hline 14.7 & 我数.1 & -0.10 .1 & -0.40 .1 & -0.17 .1 & -0.74 .1 \\
\hline 15.1 & 内容甘。 & -0.18 .1 & -0.11 .1 & -0.98 .1 & 0.96 .1 \\
\hline 16.1 & 阵园.1 & -0.29 .1 & -0.62 .1 & -0.04 .1 & -0.22 .1 \\
\hline 17.2 & E龙江. & -0.34 .1 & -0.60 .1 & 0.09 .1 & -0.42 .1 \\
\hline 18.1 & 广画.1 & -0.39 .1 & -0.51 .1 & -0.98 .1 & -0.79 .1 \\
\hline 19.1 & 讧目.1 & -0.39 .1 & -0.46 .1 & 0.04 .1 & -0.74 .1 \\
\hline 20.2 & 怣洛.1 & -0.40 .1 & 1.27 .1 & 0.53 .1 & 2. 59.1 \\
\hline 21.2 & 山园.1 & -0.45 .1 & -0.56 .1 & -0.49 .1 & -0.59 .1 \\
\hline 22.1 & 毒林.1 & -0.46 .1 & -0.33 .1 & 0.44 .1 & -0.02 .1 \\
\hline 23.1 & 因.1 & -0.50 .1 & -0.16 .1 & -0.18 .1 & -0.21 .1 \\
\hline 24.1 & 三丽.1 & -0.58 .1 & -0.59 .1 & -0.58 .1 & -1.06 .1 \\
\hline 25.1 & 部祖. & -0.77 .1 & -0.83 .1 & -0.31 .1 & -0.42 .1 \\
\hline 26.1 & 责洲. & -0.82 .1 & -0.93 .1 & -0.58 .1 & -1.01 .1 \\
\hline 27.1 & 甘角. & -0.91 .1 & -1.12 .1 & -0.36 .1 & -1.08 .1 \\
\hline 28. & 汽薾.1 & -1.10 .1 & -0.39 .1 & 2. 26.1 & -0.56 .1 \\
\hline 29.1 & 宁妾. & -1.13 .1 & -0.30 .1 & -0.98 .1 & -0.34 .1 \\
\hline 30.1 & 青海.1 & -1.17. & -0.98 .1 & -0.27 .1 & -0.51 .1 \\
\hline 31.1 & 园国. & -1.25 .1 & -0.90 .1 & -1.02 .1 & -1.16 .1 \\
\hline
\end{tabular}


表3

\begin{tabular}{|c|c|c|c|c|c|}
\hline $\begin{array}{l}\text { 排 } \\
\text { 名.1 }\end{array}$ & 地方。 & GDP 标准化. & $\begin{array}{l}\text { 居元人圽可文配 } \\
\text { 收入标准化. }\end{array}$ & $\begin{array}{l}\text { 房价收入比 } \\
\text { 标准化数据.1 }\end{array}$ & $\begin{array}{c}\text { 个人 GDP 标准 } \\
\text { 化数据. }\end{array}$ \\
\hline 20.1 & 怣伍.1 & -0.4 .1 & 1. 27.1 & 0.53 .1 & 2. 59.1 \\
\hline 13.1 & 北京. & -0.06 .1 & 2. 36.1 & 3.24 .1 & 2. 23.1 \\
\hline 11.1 & 上海.1 & 0.10 .1 & 2. 88.1 & 2.17 .1 & 2.07 .1 \\
\hline 2.1 & 江苏. & 2. 47.1 & 1. 13.1 & -0.22 .1 & 1. 30.1 \\
\hline 4.1 & 浙江. & 1. 12.1 & 1.94 .1 & 1.02 .1 & 1.01 .1 \\
\hline 15.1 & 内家古. & -0.18 .1 & $-0.11 .$. & -0.98 .1 & 0.96 .1 \\
\hline 7.1 & 这守.1 & 0.43 .1 & 0.09 .1 & -0.4 .1 & 0.68 .1 \\
\hline 1.1 & 广东. & 2.68 .1 & 1.00 .1 & 0.53 .1 & 0.54 .1 \\
\hline 12.7 & 棈注、1 & 0.08 .1 & 0.70 .1 & 0.84 .1 & 0.51 .1 \\
\hline 3.1 & 山东. & 2. 19.1 & 0.38 .1 & -0.75 .1 & 0.43 .1 \\
\hline 22.1 & 毒林. & -0.46 .1 & -0.33 .1 & 0.44 .1 & -0.02 .1 \\
\hline 23.1 & 㱐. & -0.50 .1 & -0.16 .1 & -0.18 .1 & $-0.21 .$. \\
\hline 9.1 & 湖北况 & 0.25 .1 & 0.34 .1 & -0.13 .1 & -0.22 .1 \\
\hline 16.1 & 阵面. & -0.29 .1 & -0.62 .1 & -0.04 .1 & -0.22 .1 \\
\hline 29.1 & $\dot{\mathbf{z}} \mathbf{X}$ & -1.13 .1 & -0.30 .1 & -0.98 .1 & -0.34 .1 \\
\hline 6.1 & 河北况 & 0.56 .1 & -0.32 .1 & -0.22 .1 & -0.4 .1 \\
\hline 25.1 & 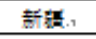 & -0.77 .1 & -0.83 .1 & -0.31 .1 & -0.42 .1 \\
\hline 17.1 & E表江. & -0.34 .1 & -0.60 .1 & 0.09 .1 & -0.42 .1 \\
\hline 10.1 & 湖南.1 & 0.25 .1 & -0.34 .1 & -0.75 .1 & -0.50 .1 \\
\hline 30.1 & 者神。 & -1.17 .1 & -0.98 .1 & -0.27 .1 & -0.51 .1 \\
\hline 28.1 & 海南. & -1.10 .1 & -0.39 .1 & 2. 26.1 & -0.56 .1 \\
\hline 21.2 & 山不. & -0.45 .1 & -0.56 .1 & -0.49 .1 & -0.59 .1 \\
\hline 5.1 & 河南.1 & 0.79 .1 & -0.43 .1 & -0.71 .1 & -0.62 .1 \\
\hline 0.1 & 四川. & 0.37 .1 & -0.50 .1 & 0.09 .1 & -0.71 .1 \\
\hline 14. & 头徶. & -0.10 .1 & -0.40 .1 & -0.17 .1 & -0.74 .1 \\
\hline 19.1 & 江可.1 & -0.39 .1 & -0.46 .1 & 0.04 .1 & -0.74 .7 \\
\hline 18.1 & 广要. & -0.39 .1 & $-0.51 .$. & -0.98 .1 & -0.79 .1 \\
\hline 26.7 & 责州, & -0.82 .1 & -0.93 .1 & -0.58 .1 & -1.01 .0 \\
\hline 24.1 & 动南.1 & -0.58 .1 & -0.59 .1 & -0.58 .1 & -1.06 .1 \\
\hline 27.1 & 甘角.1 & -0.91 .1 & -1.12 .1 & -0.36 .1 & -1.08 .1 \\
\hline 31.1 & 西局 & -1.25 .1 & -0.90 .1 & -1.02 .1 & -1.16. \\
\hline
\end{tabular}

由以上的聚类分析可知, 我国目前的房价总 体是趋于稳定的, 是比较合理的。

第一, 房价最合理的省市是天津, 尽管天 津全市的GDP不高, 但是由于人口等原因, 天津市的人均GDP及个人可支配的收入都 是很高的, 而且天津的房价收入比处在全国 的平均数之下。

第二, 广西、贵州、云南、西藏等地区虽 然经济不发达, 但是房价收入比的值较低, 可以发现, 这些省市的房价还是比较合理 的。究其原因, 还是当地人口相对较少造成 的, 在经济不发达的情况下, 房价的收入比 并不高。

第三，北京、上海、江苏、广东、海南、 浙江、福建等省市的房价是不合理的, 虽然 这些省市的GDP的总量、人均GDP的排名比 较靠前, 但是房价收入值较高, 这些城市有 一个很明显的特点就是沿海城市, 沿海城市 外来人口较多的涌入也是造成房价升高的 一个原因。同时有些开发商过度开发高档房 的现象也导致了房价的升高。

第四, 湖北、湖南、重庆、山西、吉林等 地的房价处在一个中等位置, 这些省市无论
是GDP的总量还是人均GDP以及个人可支 配收入都处在全国中等的位置, 所以这些地 方的房价处在全国的中等位置也是可以理 解的。

\section{四、对策建议}

针对中国的当家的房价问题, 可以有多种的 政策选择。

第一, 要明确清楚宏观调控的方向, 宏观调 控政策的方向一般有 3 种, 即紧缩政策, 扩 张政策, 中性政策。要采取什么政策这要根 据我国的不同时期的不同问题来决定。

第二, 区别对待。我国地域辽阔，东、中、 西部经济发展进度不尽相同, 每个地区的问 题都不完全一样。因此, 宏观政策的调控要 根据当地的具体情况作分析, 不能全国都使 用一个标准。

第三, 当地政府加大对当地房地产市场的干 预, 严格落实国家的相关政策, 对开发规模 过大。空置房较多的地区, 当地政府应该采 取相应的措施来空置供给, 减少空置。对于 房价上升过快、价格结构不平衡的地区, 应 该指导开发低价位的房, 降低开发价格, 抑 制房价过快上涨。

\section{Reference :}

[1]2013 national 31 provinces and cities GDP and per capita income list $[\mathrm{J}]$ personal finance.

[2]Focus on the housing market building enterprise.

[3] Mr Gu. The current real estate comprehensive research present situation, the trend and countermeasures. Sina.

[4]The world focus on China's house prices control. China's private wealth management network.

[5]The state council general office on promoting the real estate market stable healthy development of the notice

[6]The People's Republic of China national economic and social development statistical bulletin in 2013. The national bureau of statistics of the People's Republic of China 